San Jose State University

SJSU ScholarWorks

Faculty Publications

Chemical and Materials Engineering

$1-1-2006$

\title{
The Microstructure and Grain Size of Jet Electroplated Copper Films in Damascene Trench Features
}

Andrew Tzanavaras

San Jose State University

Gregory Young

San Jose State University

Stacy H. Gleixner

San Jose State University, stacy.gleixner@sjsu.edu

Follow this and additional works at: https://scholarworks.sjsu.edu/chem_mat_eng_pub

Part of the Other Chemical Engineering Commons, and the Other Materials Science and Engineering Commons

\section{Recommended Citation}

Andrew Tzanavaras, Gregory Young, and Stacy H. Gleixner. "The Microstructure and Grain Size of Jet Electroplated Copper Films in Damascene Trench Features" Journal of the Electrochemical Society (2006): c509-c516. https://doi.org/10.1149/1.2200287

This Article is brought to you for free and open access by the Chemical and Materials Engineering at SJSU ScholarWorks. It has been accepted for inclusion in Faculty Publications by an authorized administrator of SJSU ScholarWorks. For more information, please contact scholarworks@sjsu.edu. 


\title{
The Microstructure and Grain Size of Jet Electroplated Copper Films in Damascene Trench Features
}

\author{
Andrew Tzanavaras, Gregory Young, and Stacy Gleixner
}

Department of Chemical and Materials Engineering, San Jose State University, San Jose, California 95192

The brightening additive level and dc current density of electroplating baths are two parameters that affect the gap-filling capability and the degree of impurity incorporation in electroplated copper films. Additive incorporation can inhibit grain growth during the room temperature recrystallization process and therefore affect the final grain size. This investigation explores the grain size and microstructure of dc jet-electroplated copper films in 0.35 and $0.50 \mu \mathrm{m}$ Damascene trenches as a function of current density and brightening additive level after first receiving a high-temperature anneal. Unlike a previous study that explored these variables in blanket Cu films [J. Electrochem. Soc., 152, C101 (2005)], the results of this study suggest that current density, and to a lesser extent additive level, play a role in determining the final grain size in Damascene trenches. In $0.5 \mu \mathrm{m}$ trench structures it was found that only higher dc current density levels produce larger cross-sectional grain sizes. In $0.35 \mu \mathrm{m}$ trenches, however, both the current density and brightening additive level affected the final grain size. It thus appears that the level of geometrical constraint, the number of available nucleation sites, the amount of stored energy in the microstructure, and the degree of remnant additive incorporation are factors that could influence the final grain size.

(C) 2006 The Electrochemical Society. [DOI: 10.1149/1.2200287] All rights reserved.

Manuscript submitted June 30, 2005; revised manuscript received February 10, 2006. Available electronically May 18, 2006.

In a previous related study on the microstructure and grain size of unpatterned copper films, it was demonstrated that the current density and brightener level had no remnant effect on the final grain size or resistivity of blanket jet electrochemical deposition (JECD) copper films after a high-temperature annealing treatment. ${ }^{1}$ These results suggest that, in the absence of any geometrical constraints, grain growth inhibition factors, such as remnant electroplating impurities incorporated in the blanket film after the self-annealing process, can effectively be desorbed from these films with a sufficient thermal budget. In the current investigation, the same experimental methodology was employed to determine if these same electroplating variables had any impact on the copper microstructure in the submicrometer Damascene trench features where a high degree of geometrical constraint is imposed.

Copper is coming of age as a replacement for the interconnect metallization material used in integrated circuits due to its lower resistivity and improved electromigration resistance as compared to the aluminum alloys that were used for several decades. Unlike its aluminum counterpart, an additive fabrication process, Damascene processing is used to construct via or trench interconnect metallization structures.

Additive-enhanced electrochemical deposition (ECD) has received the most attention as the method for filling Damascene structures due to its high deposition rate, low cost of tool ownership, and the ability to fill high aspect ratio submicrometer Damascene features. JECD is a plating technique that utilizes rapid cathode rotation in conjunction with the impingement of jets of solution to sustain higher current densities and better gap-filling performance than those achieved with conventional ECD methods. ${ }^{2,3}$

Electroplated Damascene copper films are typically deposited in the presence of organic brightening additives that are used in conjunction with other organic and inorganic additives to synergistically promote the "bottom up" filling of high aspect ratio interconnect features that are free of defects such as voids and seams. Brighteners are generally organic compounds that contain sulfur and other functional groups. They function by preventing the formation of copper at preferred locations through enhancing the formation of new nuclei, as opposed to the growth of existing nuclei. ${ }^{4}$

Additive-enhanced electroplated films show a remarkable tendency to recrystallize at room temperature, and the semiconductor industry has coined the term "self-annealing" to describe this process. Room temperature recrystallization has been observed in both continuous films ${ }^{5}$ and copper deposited into Damascene trench structures. ${ }^{6}$ The activation energy for this process has been reported to be approximately $0.9-1.1 \mathrm{eV}$, which is consistent with a process controlled by the grain boundary diffusion of $\mathrm{Cu}^{7-9}$ Electrodeposited films prepared under additive-free conditions or at very low current densities do not exhibit this self-annealing behavior, thus underscoring the importance of additives in this process. ${ }^{10}$

The period required for the self-annealing process to occur can take from hours to weeks, depending on process-dependent variables such as electroplating current density, brightener concentration, film thickness, and level of geometrical constraint. ${ }^{10-12}$ These electroplating variables can lead to different defect densities in the as-deposited films that influence not only the kinetics of the transformation but also the final grain size and degree of (111) fiber texture. ${ }^{13}$ The grain size dependence is related to the degree of impurity incorporation in the grain boundaries after the self-annealing process, which poses limitations to further grain growth. ${ }^{11,14,15}$

Due to the relatively slow kinetics of the room temperature recrystallization process, some type of high-temperature thermal annealing treatment is generally used to accelerate the process. ${ }^{16-21}$ In addition to increasing production throughput, thermal annealing of the self-annealed copper microstructure has been reported to have additional material benefits. These include a slight lowering of the final film resistivity to near-bulk values, ${ }^{20}$ additional grain growth, ${ }^{13}$ and higher CMP removal rates of the copper overburden. ${ }^{10}$

\section{Experimental}

The experimental setup, including the composition of the acid copper sulfate electroplating bath, was the same as that used in the authors' previous study on blanket $\mathrm{Cu}$ films. ${ }^{1} 1.3 \mu \mathrm{m}$ thick $\mathrm{Cu}$ films were deposited using the jet-agitation electroplating method and acid copper sulfate chemistry on patterned $200 \mathrm{~mm}$ Si wafers with arrays of Damascene trench structures.

Direct current (dc) electroplating of the $\mathrm{Cu}$ films was performed with a Jets Technology Jet Electroplating System. This system is designed with a stationary cathode (wafer) and a rotating anode jet assembly (RAJA), which are in close proximity and oriented coaxially with respect to one another. As compared to more conventional methods of solution agitation, the jet-electroplating method facilitates improved gap filling and allows the use of significantly higher current densities by decreasing the length of the diffusion layer., ${ }^{2,3}$ The higher current densities, in turn, allow for plating at substantially higher rates without sacrificing the gap-filling requirements of the copper Damascene process. ${ }^{2}$

The wafer samples contain sixty-nine identical $20 \mathrm{~mm}$ dice that are patterned with via and trenched regions of varying geometries and pitch densities. The mask layout for each of these sixty-nine dice is shown in Fig. 1. These wafers are $200 \mathrm{~mm}, \mathrm{Si}(100)$ wafers with an etched $0.8 \mu \mathrm{m}$ plasma enhanced tetraethylorthosilicate (PETEOS) $\mathrm{SiO}_{2}$ layer, a 25-30 nm CVD Ta barrier layer, and a $125 \mathrm{~nm}$ composite chemical vapor deposition-physical vapor deposited (CVD-PVD) $\mathrm{Cu}$ seed layer. A cross-sectional view of a typical 


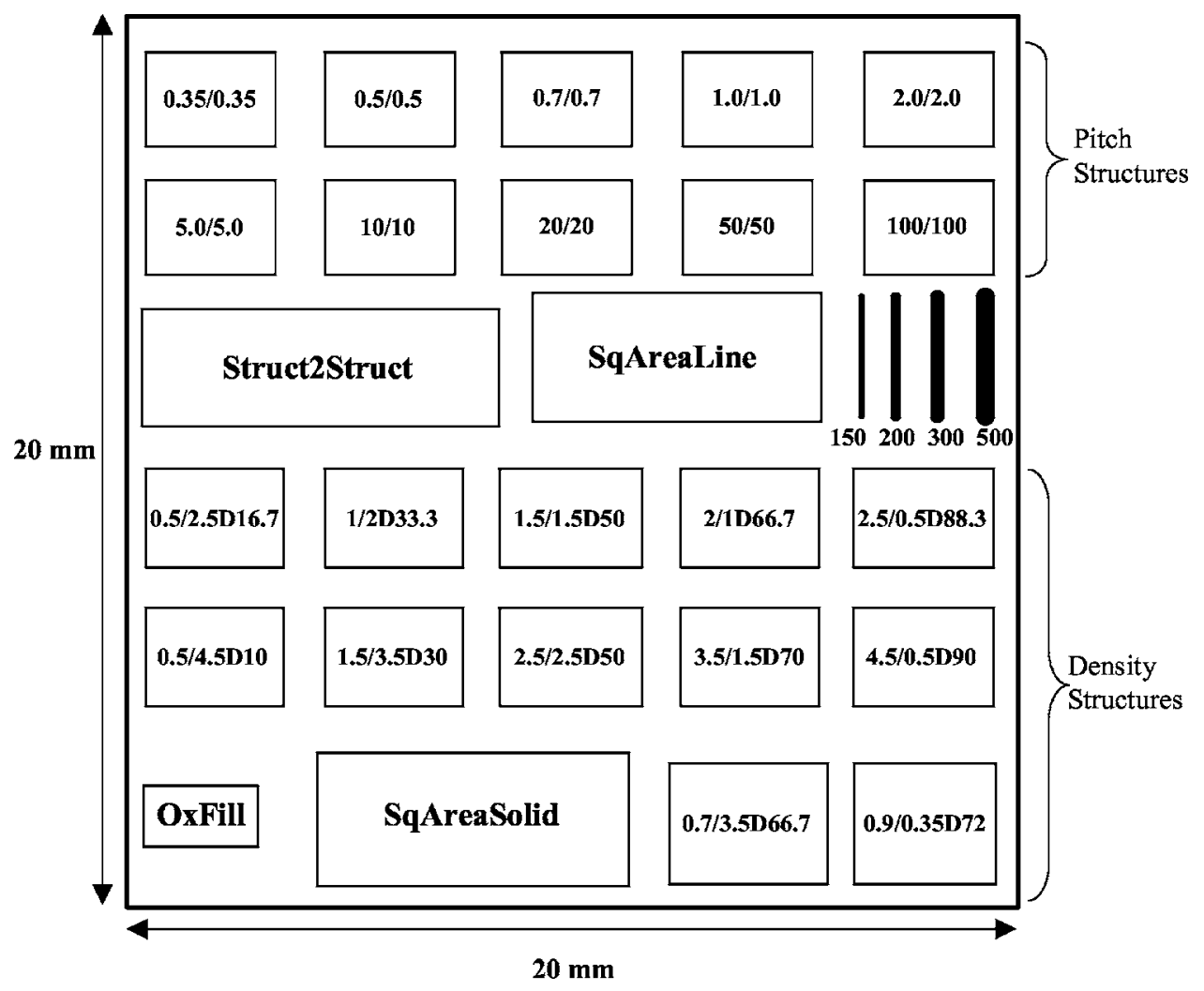

Figure 1. The mask layout for each of the sixty-nine identical $20 \mathrm{~mm}$ square die on the $200 \mathrm{~mm}$ wafers used in this study. The $0.5 / 0.5$ and $0.35 / 0.35$ pitch density trench structures were used in this investigation. A $0.5 / 0.5$ structure implies $0.5 \mu \mathrm{m}$ linewidths, with $0.5 \mu \mathrm{m}$ line spacings. ${ }^{22}$ trench structure, which also includes the electroplated copper, is shown in Fig. 2. ${ }^{22}$ In this study, the grain density, which is defined as the number of grains per unit cross-sectional area, and $\mathrm{Cu}$ microstructure were analyzed in trench features with line widths of 0.50 and $0.35 \mu \mathrm{m}$ for each experimental condition. It is important to note that a larger grain density implies a smaller grain size.

The two variables of interest were the brightener activity level and the dc current density used in the electrodeposition process. Three levels, designated as low, medium, and high, were used for each of these two electroplating variables to construct a $3^{2}$ fullfactorial experimental design matrix. Two replications were performed for each of the nine unique conditions. A summary of these nine conditions can be found in Table I and deposition parameters common to all nine experimental conditions are given in Table II. Upon completion of the deposition matrix, all samples were annealed in a quartz tube chamber at $400^{\circ} \mathrm{C}$ for $30 \mathrm{~min}$ in a forming gas environment composed of $4 \% \mathrm{H}_{2} / 96 \% \mathrm{~N}_{2}$.

The current density corresponding to each experimental condition was determined by dividing the wafer surface area by the applied dc current to the anode. The brightener level was determined from its chemical activity in the acid copper sulfate bath by con-

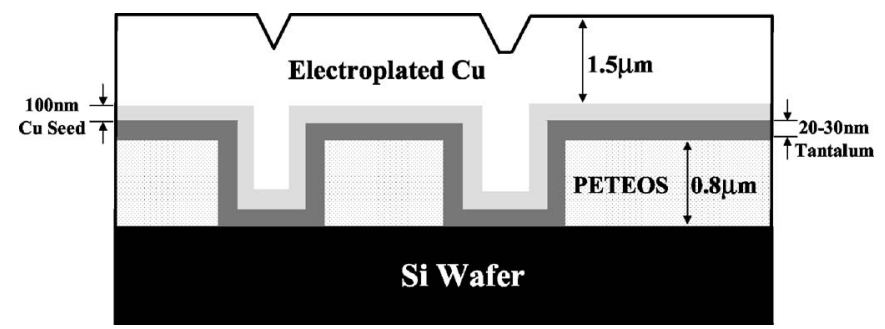

Figure 2. A cross-sectional view of a typical Damascene trench structure for the wafers used in this investigation. The layer thicknesses for each of the materials in this system are indicated. The electroplated $\mathrm{Cu}$ layer was the focus of this study. ${ }^{22}$ structing a calibration curve based on the cyclic voltammetric stripping (CVS) technique..$^{23,24}$ The range of absolute concentrations used to construct the calibration curve was $0.0-2.50 \mathrm{~mL} / \mathrm{L}$ in increments of $0.50 \mathrm{~mL} / \mathrm{L}$, requiring a total of six data points. For each analysis, a constant scan rate of $100 \mathrm{mV} / \mathrm{s}$ was used between switching potentials of -2.3 and $1.5 \mathrm{~V}$. From these data, an arbitrary chemical activity number, $A_{B}$, was calculated by normalizing these interpolated anodic peak areas to the area measured from the CVS scan for the brightener-free bath condition.

In order to characterize the grain density and microstructure of the $\mathrm{Cu}$ films within the patterned regions, tilt-view focused ion beam (FIB) images were obtained in the 0.35 and $0.50 \mu \mathrm{m}$ trenches using an FEI 820 Dual-beam FIB-scanning electron microscope (SEM) system. ${ }^{25}$ Before such images could be acquired, a rectangular region of the $\mathrm{Cu}$ film was first coarse-milled down to the $\mathrm{Si}$ wafer using a beam current of $2700 \mathrm{pA}$ and then fine-milled at $1000 \mathrm{pA}$ to expose the trenches for imaging. Figure 3 shows a milled rectangular region with an array of $0.5 \mu \mathrm{m}$ trenches exposed for imaging. A beam voltage of $30 \mathrm{kV}$ and a beam current of $5 \mathrm{pA}$ were the pri-

Table I. A summary table outlining the experimental matrix for this investigation. There are two electroplating variables, each at three levels, making this a $3^{2}$ full-factorial design experiment.

\begin{tabular}{ccc} 
Condition & $\begin{array}{c}\text { Current density } \\
\left(\mathrm{mA} / \mathrm{cm}^{2}\right)\end{array}$ & $\begin{array}{c}\text { Additive level } \\
(\mathrm{mL} / \mathrm{L})\end{array}$ \\
\hline 1 & $15($ low $)$ & $0.75($ low $)$ \\
2 & $45($ medium) & $0.75($ low $)$ \\
3 & 105 (high) & 0.75 (low) \\
4 & $15($ low $)$ & 1.50 (medium) \\
5 & $45($ medium) & 1.50 (medium) \\
6 & 105 (high) & 1.50 (medium) \\
7 & 15 (low) & 2.25 (high) \\
8 & $45($ medium) & 2.25 (high) \\
9 & 105 (high) & 2.25 (high)
\end{tabular}




\begin{tabular}{cc}
\hline $\begin{array}{l}\text { Table II. The electrochemical deposition parameters common to } \\
\text { all nine conditions of the experimental matrix. } \\
\text { Parameter }\end{array}$ Value \\
\hline Jet nozzle pressure & $40 \mathrm{pPsi}$ \\
Plating solution flow rate & $3.5-3.8 \mathrm{gpm}$ \\
RAJA rotation speed & $20 \mathrm{rpm}$ \\
Anode-cathode spacing & $2.8 \mathrm{~cm}$ \\
Anode-cathode area ratio & $0.75: 1$ \\
Deposition temperature & $21.5 \pm 1.0^{\circ} \mathrm{C}$
\end{tabular}

mary imaging parameters, with the sample tilted $38^{\circ}$ from the wafer surface. Magnifications of 35000 and 50000 times were used to assess the $\mathrm{Cu}$ microstructure in both trench sizes. Cross-sectional electron images were also acquired to assess the gap-filling quality within these trench features.

\section{Results and Discussion}

Figure 4 illustrates representative FIB images from experimental condition 5 taken at a tilt angle of $52^{\circ}$ relative to the surface normal at 35000 times magnification. The large grains in these images illustrate that the $\mathrm{Cu}$ within these fine trench features appears to be fully recrystallized, as there is no evidence of a fine-grained component. The grains in the $0.5 \mu \mathrm{m}$ lines are observed to be larger than those of the $0.35 \mu \mathrm{m}$ lines, which is consistent with the observation that grain size within Damascene features decreases linearly with trench width. ${ }^{26}$

The occurrence of twinning is observed to be common within these features, especially in the larger grains. There is a tendency for some grains in the overlying copper to propagate into the trench structures during the grain growth process. Jiang et al. observed this behavior in a previous study. ${ }^{12}$ Within these features, a variety of grain sizes were found, but occasionally very large grains, which occupied the entire width and a large percentage of the trench crosssectional area, were observed. The semiconductor industry generally refers to this grain structure as a "bamboo" microstructure. The shape, size, and location of some grains suggest that surfaces within the trench can serve as nucleation sites during the recrystallization process.

To better discern the grains within the trench features of the 0.35 and $0.50 \mu \mathrm{m}$ trenches in this study, additional FIB cross sections were taken at 50000 times magnification. Representative images of grain structure are shown in Fig. 5. From these images it is apparent

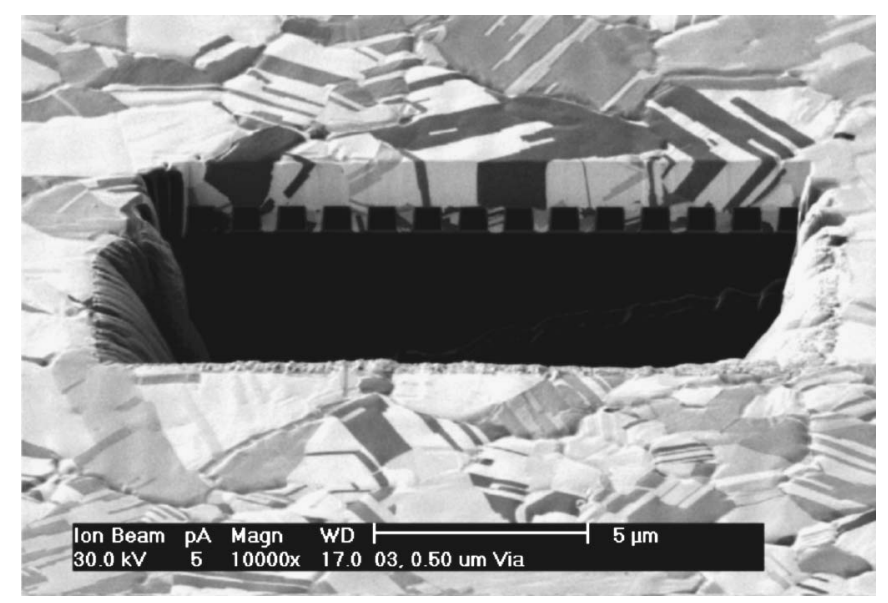

Figure 3. A tilt-view 10000 times ion image showing a rectangular region of the wafer milled down to the $\mathrm{Si}$ substrate to expose an array of $0.5 \mu \mathrm{m}$ trench structures containing electroplated $\mathrm{Cu}$. A variety of microstructural features, including large, recrystallized, highly twinned $\mathrm{Cu}$ grains, can easily be seen.

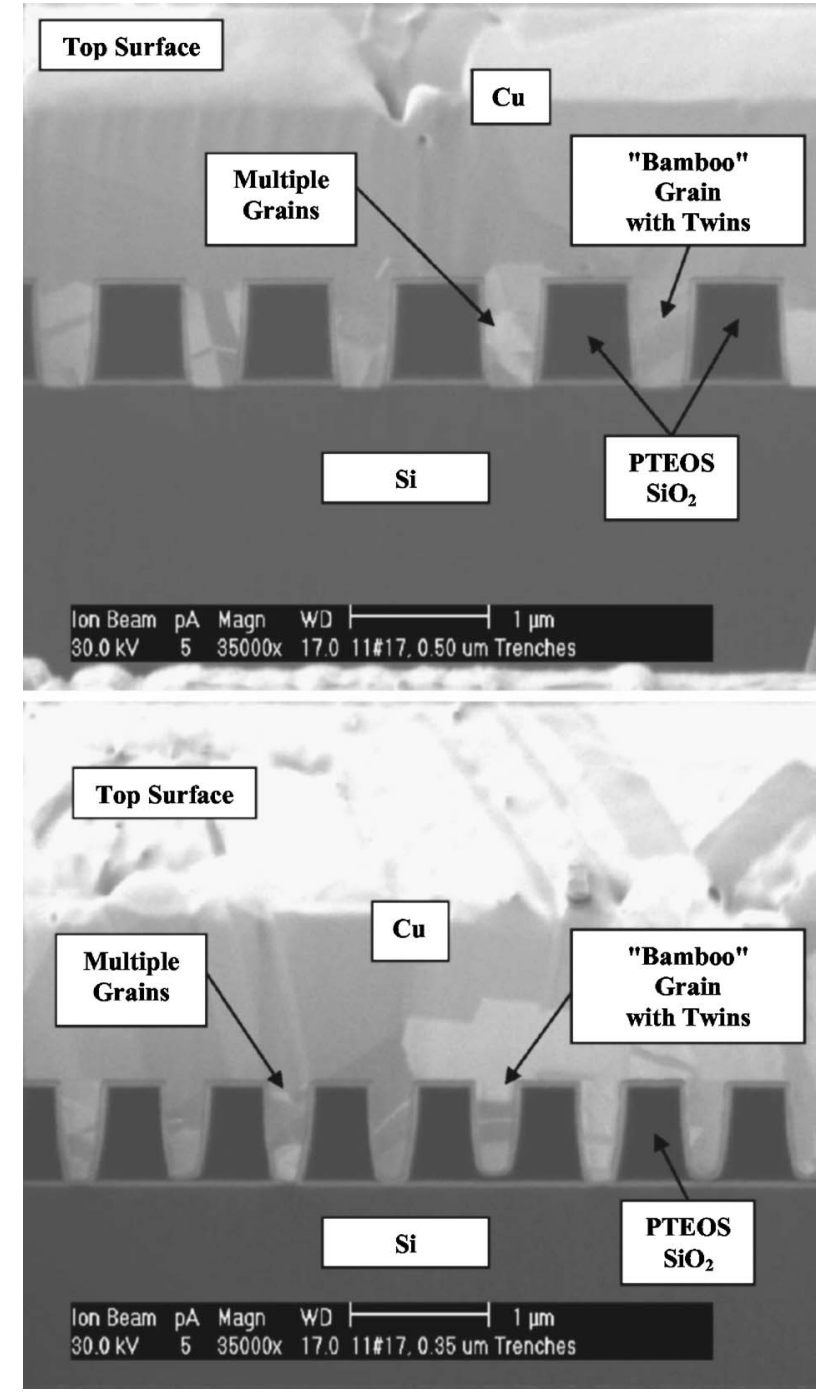

Figure 4. Representative tilt-view FIB images taken at 35000 times magnification for condition 5 , showing the grain structure within $0.50 \mu \mathrm{m}$ (top) and $0.35 \mu \mathrm{m}$ (bottom) Damascene trench structures in cross section.

that a wide variety of grain structures exist with these features. In some cases, large grains occupy approximately $50-100 \%$ of the trench cross-sectional area. In other cases, several small grains occupy the trench, with a wide variety of shapes and sizes. Hence, even with a high-temperature annealing treatment, it is not necessarily true that large grains will occupy all of, or even a significant portion of, the cross-sectional area encompassed by fine trench features. This suggests that other factors, such as the nucleation and growth processes that occur during electrodeposition, can lead to as-deposited structures with different amounts of stored energy. These differences could influence not only the recrystallization kinetics but also the final recrystallized microstructure within fine trench or via structures.

A grain size analysis was performed for all nine experimental conditions on both the 0.35 and $0.50 \mu \mathrm{m}$ trench features using the tilt-view FIB images taken at 35000 times magnification. In all cases, the same die from each experimental wafer was used. The grains within ten $0.50 \mu \mathrm{m}$ feature and fourteen $0.35 \mu \mathrm{m}$ feature trenches were considered for the analysis. Similar to the work of Ritzdorf et al., the grain size was quantified as the grain density, which is the number of grains per unit cross-sectional trench area. Using this grain density index, a larger value is indicative of a smaller cross-sectional grain size. Image analysis software was uti- 

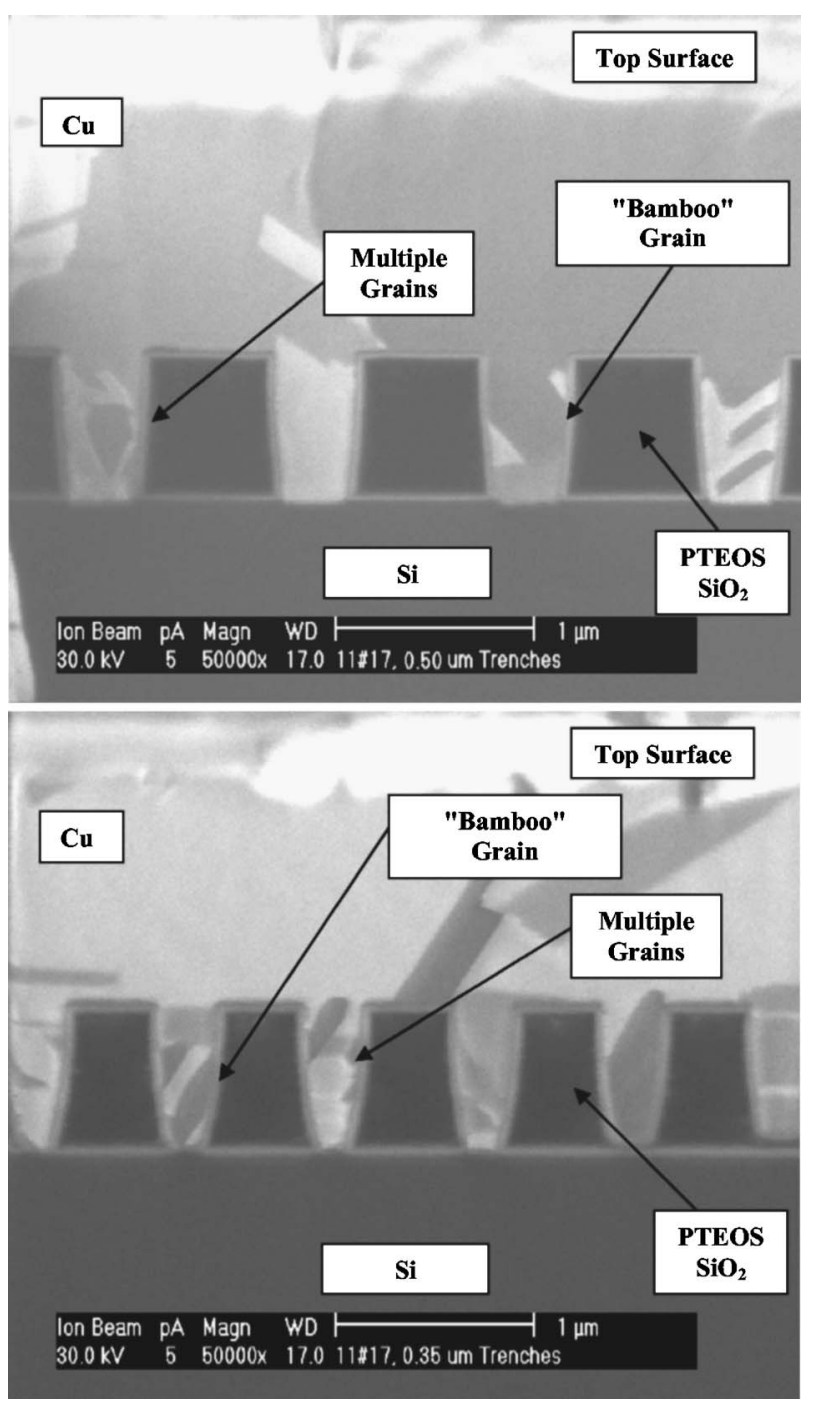

Figure 5. Representative tilt-view FIB images taken at 50000 times magnification for condition 5 , showing the grain structure within $0.50 \mu \mathrm{m}$ (top) and $0.35 \mu \mathrm{m}$ (bottom) Damascene trench structures in cross section.

lized to calculate the cross-sectional area of each trench and to enhance the image as necessary to detect grains that were difficult to discern. ${ }^{27}$ Tables III and IV summarize the results of this analysis

Table III. A summary of the grain density results for the $0.5 \mu \mathrm{m}$ trench features. A smaller grain density implies a larger, average, cross-sectional grain size. Ten trenches were sampled for each experimental condition.

\begin{tabular}{ccccc} 
Condition & $\begin{array}{c}\text { Average } \\
\text { grains } \\
\text { per } \\
\text { trench }\end{array}$ & $\begin{array}{c}\text { Average } \\
\text { trench } \\
\text { area } \\
\left(\mu \mathrm{m}^{2}\right)\end{array}$ & $\begin{array}{c}\text { Average } \\
\text { grain } \\
\text { density } \\
\left(\text { grains/ } \mu \mathrm{m}^{2}\right)\end{array}$ & $\begin{array}{c}\text { Grain } \\
\text { density } \\
\text { standard } \\
\text { deviation } \\
\left(\text { Grains/ } \mu \mathrm{m}^{2}\right)\end{array}$ \\
\hline 1 & 3.20 & 0.305 & 10.49 & 0.21 \\
2 & 3.00 & 0.309 & 9.71 & 0.23 \\
3 & 2.80 & 0.307 & 9.12 & 0.21 \\
4 & 3.40 & 0.295 & 11.53 & 0.24 \\
5 & 3.10 & 0.300 & 10.33 & 0.26 \\
6 & 2.80 & 0.296 & 9.46 & 0.24 \\
7 & 3.40 & 0.298 & 11.41 & 0.17 \\
8 & 3.30 & 0.344 & 9.59 & 0.20 \\
9 & 2.80 & 0.297 & 9.43 & 0.25
\end{tabular}

Table IV. A summary of grain density results for $0.35 \mu \mathrm{m}$ trench features. A smaller grain density implies a larger, average, crosssectional grain size. Fourteen trenches were sampled for each experimental condition.

\begin{tabular}{ccccc} 
Condition & $\begin{array}{c}\text { Average } \\
\text { grains } \\
\text { per } \\
\text { trench }\end{array}$ & $\begin{array}{c}\text { Average } \\
\text { trench } \\
\text { area } \\
\left(\mu \mathrm{m}^{2}\right)\end{array}$ & $\begin{array}{c}\text { Average } \\
\text { grain } \\
\text { density } \\
\left(\text { grains/ } \mu \mathrm{m}^{2}\right)\end{array}$ & $\begin{array}{c}\text { Grain } \\
\text { density } \\
\text { standard } \\
\text { deviation } \\
\left(\text { Grains/ } \mu \mathrm{m}^{2}\right)\end{array}$ \\
\hline 1 & 3.43 & 0.180 & 19.05 & 0.22 \\
2 & 3.57 & 0.187 & 19.10 & 0.23 \\
3 & 2.57 & 0.206 & 12.48 & 0.19 \\
4 & 4.00 & 0.180 & 22.22 & 0.15 \\
5 & 3.86 & 0.189 & 20.41 & 0.24 \\
6 & 2.86 & 0.207 & 13.80 & 0.28 \\
7 & 4.14 & 0.170 & 24.37 & 0.19 \\
8 & 4.07 & 0.185 & 23.95 & 0.23 \\
9 & 2.43 & 0.189 & 12.85 & 0.25
\end{tabular}

for each condition.

Figures 6 and 7 are plots of the grain density as a function of current density for each of the three additive levels used in this study, for both the $0.50 \mu \mathrm{m}$ and $0.35 \mu \mathrm{m}$ features, respectively. It is emphasized that the grain densities represented are perpendicular and not parallel to the current path. Consequently, no conclusions can be made from these data about the grain size and grain structure parallel to the trenches. Figure 6 shows a tendency for the grain density to decrease with current density after recrystallization in the $0.5-\mu \mathrm{m}$ trenches but no obvious trend with respect to the additive level. The incongruous data point for experimental condition 8 is probably a consequence of the larger-than-typical cross-sectional trench areas for this condition $\left(0.344 \mu \mathrm{m}^{2}\right)$ as compared to the remaining seven conditions $\left(0.295-0.309 \mu \mathrm{m}^{2}\right)$ used to calculate the grain density.

To determine the statistical relevance of these trends, analysis of variance (ANOVA) with replication was performed at the $95 \%$ confidence level $(\alpha=0.05)$ on the entire $0.50 \mu \mathrm{m}$ data set. ${ }^{28}$ The results are presented in tabular form in Table V. Table $\mathrm{V}$ shows that the current density, additive level, and their interactions all do not have a significant influence on grain size at the $95 \%$ confidence level. A p-value of 0.09 implies significance at the $91 \%$ confidence level.

In reviewing Fig. 6, it was mentioned that condition 8 was generally incongruous with the other data shown, which was attributed

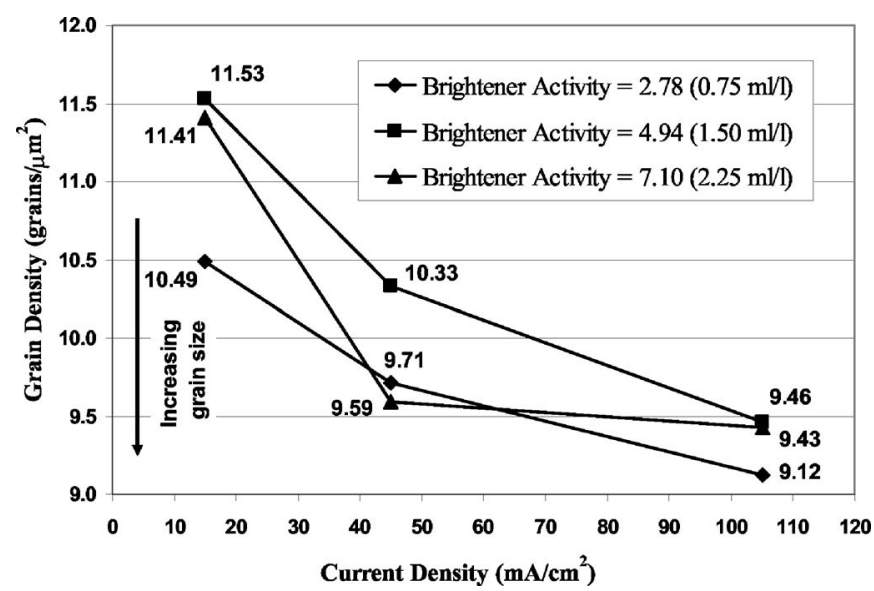

Figure 6. A plot showing the trends in grain density within the $0.50 \mu \mathrm{m}$ trenches for all nine experimental conditions. The incongruous grain density data point obtained for experimental condition $8\left(9.59\right.$ grains $\left./ \mu \mathrm{m}^{2}\right)$ may have been a consequence of the larger cross-sectional areas of the $0.50 \mu \mathrm{m}$ trenches measured on this wafer. 


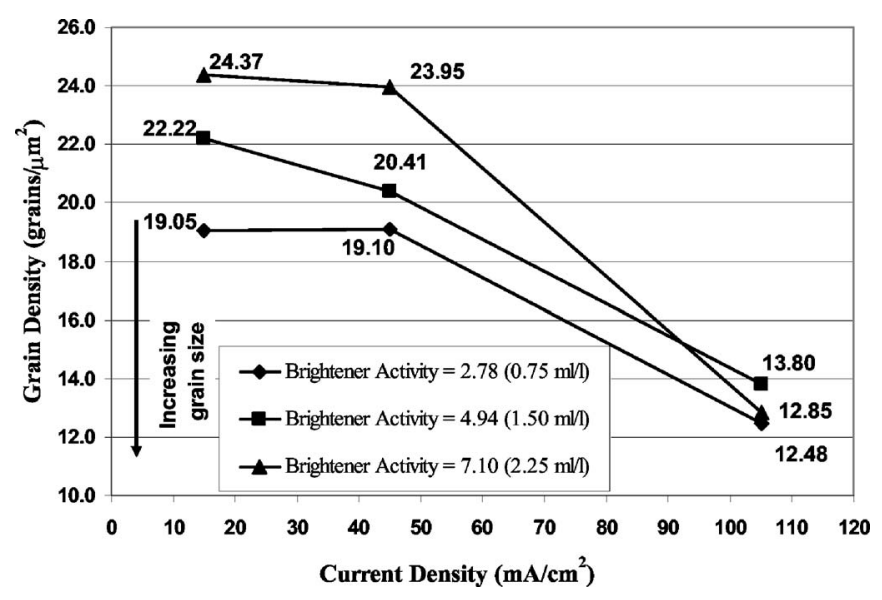

Figure 7. A plot showing the trends in grain density within the $0.35 \mu \mathrm{m}$ trenches for all nine experimental conditions. The data suggest a stronger tendency for the grain size to increase with current density $\left(45-105 \mathrm{~mA} / \mathrm{cm}^{2}\right)$, as compared to the $0.50 \mu \mathrm{m}$ trenches.

to the larger trench areas for this condition (Table IV). To remove the effects of this data point and gain further insights, there are two methods that can be used to circumvent this problem and reanalyze the data. One method is to collapse the analysis into an experimental design in which only the extreme values of current density (15 and $105 \mathrm{~mA} / \mathrm{cm}^{2}$ ) are considered at the three additive levels. Alternatively, a correction can be made to the cross-sectional area for condition 8 , based on the average value for the remaining eight conditions. Both methods were considered and the ANOVA results are shown in Tables VI and VII, respectively. With the former method (Table VI), it is clear that the current density becomes significant at the $95 \%$ confidence level. With the latter method (Table VII), however, there is only statistical significance at the $89 \%$ confidence level. Based on these modified analyses, it appears that increasing current density has only a minor influence, at best, on the final grain size in the $0.50 \mu \mathrm{m}$ features. In order to assign a more precise level of confidence, further analysis of condition 8 would be required. Additive level, or the interaction of additive level with current density, is shown to exert no significant influence at the $95 \%$ confidence with either approach.

Figure 7 shows there is a stronger influence exerted by the current density in the $0.35 \mu \mathrm{m}$ features, as compared to the $0.50 \mu \mathrm{m}$ features. Furthermore, the trend suggests the additive level might play a minor role with respect to the recrystallized grain size in the low to intermediate current density range. Similar to the $0.50 \mu \mathrm{m}$ trench results, there is very little difference in the final grain size with respect to additive level at the highest current density level. ANOVA was performed on the entire data set and the results are shown in Table VIII. The results of this analysis reveal that increasing the current density or decreasing the additive level both have a positive effect on grain size at the 95\% confidence level. However, current density is the dominant effect, as its p-value is several orders of magnitude smaller.

\begin{tabular}{|c|c|c|c|c|c|c|}
\hline Source of variation & df & SS & MS & Fcalc & Fcrit & $p$-value \\
\hline Current density & 2 & 51.54 & 25.77 & 2.48 & 3.11 & 0.090 \\
\hline Additive activity & 2 & 6.67 & 3.34 & 0.32 & 3.11 & 0.727 \\
\hline Variable interaction & 4 & 3.61 & 0.90 & 0.09 & 2.48 & 0.986 \\
\hline Error & 81 & 843.33 & 10.41 & & & \\
\hline Total & 89 & 905.16 & & & & \\
\hline
\end{tabular}

\begin{tabular}{|c|c|c|c|c|c|c|}
\hline Source of variation & $\mathrm{df}$ & SS & MS & Fcalc & Fcrit & $p$-value \\
\hline Current density & 1 & 48.94 & 48.94 & 5.22 & 4.02 & 0.03 \\
\hline Additive activity & 2 & 5.68 & 2.84 & 0.30 & 3.17 & 0.74 \\
\hline Variable interaction & 2 & 1.44 & 0.72 & 0.08 & 3.17 & 0.93 \\
\hline Error & 54 & 505.87 & 9.37 & & & \\
\hline Total & 59 & 561.93 & & & & \\
\hline
\end{tabular}

In reexamining the data trends shown in Fig. 7, it appears that current density plays a much more dominant role in determining the final grain size in going from 45 to $105 \mathrm{~mA} / \mathrm{cm}^{2}$. Additive activity appears to exert a significant influence in going from 15 to $45 \mathrm{~mA} / \mathrm{cm}^{2}$. To further understand these two trends, two separate ANOVA analyses were performed in this regard. The ANOVA analysis shown in Table IX considers only the 15 and $45 \mathrm{~mA} / \mathrm{cm}^{2}$ current density levels for all three levels of brightening additive activity. Similarly, Table X considers only the 45 and $105 \mathrm{~mA} / \mathrm{cm}^{2}$ current density levels for all three levels of brightening additive activity. These tables show that the trends mentioned above in relation to Fig. 7 both have statistical significance at the $95 \%$ confidence level. In comparing the two analyses shown in Tables IX and X, however, the current density is a far more dominant effect.

In summary, the results of this study suggest that within $0.35 \mu \mathrm{m}$ trenches there is a strong tendency for the grain size to increase with current density over a current density range of $45-105 \mathrm{~mA} / \mathrm{cm}^{2}$ at the $95 \%$ confidence level. A similar but weaker tendency is exhibited in the $0.50 \mu \mathrm{m}$ trenches at approximately the $90 \%$ confidence level. Within the current density range of $15-45 \mathrm{~mA} / \mathrm{cm}^{2}$, increasing the brightener level tends to produce smaller grains in $0.35 \mu \mathrm{m}$ trenches at the $95 \%$ confidence level. The mechanisms underlying these dependencies are unclear at this time, but the following discussion proposes some possible explanations.

Electroplated copper within Damascene trenches does not recrystallize as readily as the bulk film and a larger thermal budget is required as geometries continue to shrink. ${ }^{9,00,12,26,29}$ Furthermore, annealing conditions are a function of trench line width, and smaller trench sizes generally require more thermal energy to achieve full recrystallization than larger trench sizes. ${ }^{9}$ Even in blanket films, self-annealing will not occur when the film thickness becomes less than approximately $0.50 \mu \mathrm{m} .^{7,8,11}$ These facts suggest that the ability of electroplated films to recrystallize in fine features depends on geometrical factors that limit grain growth, the number of available sites for nucleation, and the amount of energy stored in the asdeposited films. ${ }^{8}$ Implied with these tendencies is the possibility of a higher activation energy for recrystallization in these fine features.

In the current study, it has been shown that current density is a significant factor affecting the final grain size in fine Damascene trenches after allowing sufficient time for self-annealing, followed by a high-temperature annealing treatment. In both 0.35 and $0.50 \mu \mathrm{m}$ features, the higher current densities tend to produce larger final grain sizes. However, this factor has been shown to also be line-width-dependent, in that the effect was far more pronounced for

Table VII. Modified ANOVA results at the $95 \%$ confidence level for the $0.50 \mu \mathrm{m}$ grain density data that employ a trench area correction to experimental condition 8 .

\begin{tabular}{lcrrrrr} 
Source of variation & df & \multicolumn{1}{c}{ SS } & \multicolumn{1}{c}{ MS } & Fcalc & Fcrit & $p$-value \\
\hline Current density & 2 & 49.13 & 24.56 & 2.30 & 3.11 & 0.11 \\
Additive activity & 2 & 11.52 & 5.76 & 0.54 & 3.11 & 0.58 \\
Variable interaction & 4 & 3.46 & 0.87 & 0.08 & 2.48 & 0.99 \\
Error & 81 & 864.29 & 10.67 & & & \\
Total & 89 & 928.40 & & & &
\end{tabular}




\begin{tabular}{|c|c|c|c|c|c|c|}
\hline Source of variation & df & SS & MS & Fcalc & Fcrit & $p$-value \\
\hline Current density & 2 & 2020.35 & 1010.18 & 26.94 & 3.07 & $2.38 \mathrm{E}-10$ \\
\hline Additive activity & 2 & 260.11 & 130.05 & 3.47 & 3.07 & 0.03 \\
\hline Variable interaction & 4 & 129.98 & 32.49 & 0.87 & 2.45 & 0.49 \\
\hline Error & 117 & 4387.51 & 37.50 & & & \\
\hline Total & 125 & 6797.95 & & & & \\
\hline
\end{tabular}

the smaller trench geometry. Considering the available information on copper recrystallization, it is proposed that after the selfannealing process, the small trench features were at best only partially recrystallized. ${ }^{9}$ The $0.50 \mu \mathrm{m}$ trenches, however, would be expected to have exhibited a much larger degree of recrystallization. ${ }^{9}$

The high-temperature annealing treatment then completed the recrystallization process within these features and possibly led to some post-recrystallization grain growth. The current density dependence can be understood by considering that higher current densities generally lead to higher defect densities and lower impurity levels in the as-deposited film. ${ }^{13,30}$ The films deposited at higher current densities would thus be expected to exhibit faster recrystallization kinetics due to the presence of a higher driving force for recrystallization resulting from more stored energy in the film and less graingrowth inhibition from incorporated additives. ${ }^{7,13,14}$ Alternatively, with geometrical constraints and a limited number of nucleation sites, it is also possible that the ratio of the nucleation to growth rates during the recrystallization process may change as a function of current density within these fine features. Ultimately, either of these events could lead to a larger final grain size and the increased potential for a "bamboo" microstructure with an adequate thermal budget within fine Damascene features. The dependence of grain size on current density in these fine features could be a manifestation of a similar phenomenon seen in self-annealed blanket films. The primary differences between the self-annealing of blanket films and the thermal recrystallization in small trench features would be faster kinetics arising from the high-temperature treatment and less opportunity for nucleation and growth due to the imposed geometrical constraints.

Annealing under high-energy conditions, even after recrystallization, will generally always result in some additional grain growth. However, unlike blanket films, the grain growth in these fine features becomes limited by geometrical constraints. Hence, the additional post-recrystallization grain growth arising from the thermal treatment after the self-annealing process in the blanket films did not occur to the same degree in the 0.35 and $0.50 \mu \mathrm{m}$ features due to the inherent geometrical restrictions on growth. Such restrictions also explain why the $0.50 \mu \mathrm{m}$ feature size exhibits a somewhat larger final grain size as compared to the $0.35 \mu \mathrm{m}$ feature size. The results of this study show that increasing the level of geometrical constraint makes the entire system more sensitive to the current density level.

In addition to the current density effect, it also appears that the additive level could become a more significant factor affecting the final grain size in Damascene features as interconnect geometries continue to shrink. It was shown in this study that the additive level

Table IX. Modified ANOVA results at the $\mathbf{9 5 \%}$ confidence level for the $0.35 \mu \mathrm{m}$ grain density data that consider only the low and medium current density levels for all three additive levels.

\begin{tabular}{lcrrrrr} 
Source of variation & df & \multicolumn{1}{c}{ SS } & \multicolumn{1}{c}{ MS } & Fcalc & Fcrit & $p$-value \\
\hline Current density & 1 & 11.12 & 11.12 & 0.33 & 3.96 & 0.57 \\
Additive activity & 2 & 363.92 & 181.96 & 5.41 & 3.11 & 0.01 \\
Variable interaction & 2 & 13.17 & 6.58 & 0.20 & 3.11 & 0.82 \\
Error & 78 & 2625.09 & 33.66 & & & \\
Total & 83 & 3013.30 & & & &
\end{tabular}

\begin{tabular}{|c|c|c|c|c|c|c|}
\hline Source of variation & df & SS & MS & Fcalc & Fcrit & $p$-value \\
\hline Current density & 1 & 1380.24 & 1380.24 & 34.42 & 3.96 & $1.02 \mathrm{E}-07$ \\
\hline Additive activity & 2 & 95.30 & 47.65 & 1.19 & 3.11 & 0.31 \\
\hline Variable interaction & 2 & 94.05 & 47.03 & 1.17 & 3.11 & 0.31 \\
\hline Error & 78 & 3128.14 & 40.10 & & & \\
\hline Total & 83 & 4697.72 & & & & \\
\hline
\end{tabular}

had a substantial negative effect on grain size within $0.35 \mu \mathrm{m}$ trench sizes at both low and intermediate current density levels; a similar effect was not observed in $0.50 \mu \mathrm{m}$ trenches. If it were assumed that the grains in the trenches were only partially recrystallized prior to the high-temperature annealing process, the microstructure would possess a substantial fine-grained component after one week. ${ }^{10}$ These small grains would be expected to have a high defect density, a high grain boundary energy density, and a significant degree of additive incorporation. It would also be expected that the $0.35 \mu \mathrm{m}$ trenches would be affected more than the larger $0.50 \mu \mathrm{m}$ trenches. However, as compared to large-grained films, there would be much more grain boundary volume by which the additives could diffuse through the trench volume during the high-temperature treatment. The overlying large-grained microstructure, however, could pose rate limitations for this process, in that some incorporated additives remain trapped in the trench films after the high-temperature annealing treatment. These incorporated additives, in turn, could impose grain growth inhibition by acting as pinning sites at the grain boundaries.

With respect to the electroplating variables used in this investigation, it has been shown that the smallest grain densities, or largest cross-sectional grain sizes, were achieved at the highest current density level $\left(105 \mathrm{~mA} / \mathrm{cm}^{2}\right)$ for all nine experimental conditions in either trench size. Larger grain sizes would be favored in any manufacturing process; as such, a microstructure would result in faster and more reliable devices. The higher deposition rates associated with the use of high current densities would also be the most technologically relevant due to the shorter deposition times. Because the success or failure of any semiconductor metallization process is also predicated on the ability to adequately fill fine features with high aspect ratios (AR), the gap-filling capabilities were also examined for conditions that employed the highest current density level (conditions 3, 6, and 9).

Representative cross-sectional electron images at 65000 times magnification of the filled $0.50 \mu \mathrm{m}$ and $0.35 \mu \mathrm{m}$ trench features are shown in Fig. 8 for experimental conditions 3, 6, and 9. The images show that no voids or seams exist in any of the $0.50 \mu \mathrm{m}$ trenches for any of the three conditions. Within the $0.35 \mu \mathrm{m}$ structures, however, condition 6 illustrates the presence of two distinct crescent-shaped bottom voids (circled), whereas conditions 3 and 9 are defect-free. The shape and location of these voids would generally be associated with the voiding that tends to arise from poor step coverage of the seed layer near the bottom of the trench. The adjacent trench immediately to the left, however, shows no void defects. Because the trench separation is approximately equal to the trench width, it seems unlikely that the step coverage of the seed layer would be adequate in one trench and poor in an adjacent trench of very close proximity. A previous study has shown that the dewetting or agglomeration of copper from the underlying barrier material during thermal processing can also lead to voiding at the bottom of Damascenes trenches, which offers one possible explanation. ${ }^{31}$ In summary, the gap filling was generally good for the three experimental conditions that employed the highest current density and produced the largest $\mathrm{Cu}$ grains, with the exception of the voids found at the base of the $0.35 \mu \mathrm{m}$ features for experimental condition 6 . A more exhaustive investigation would be required to determine the origins of this voiding. 

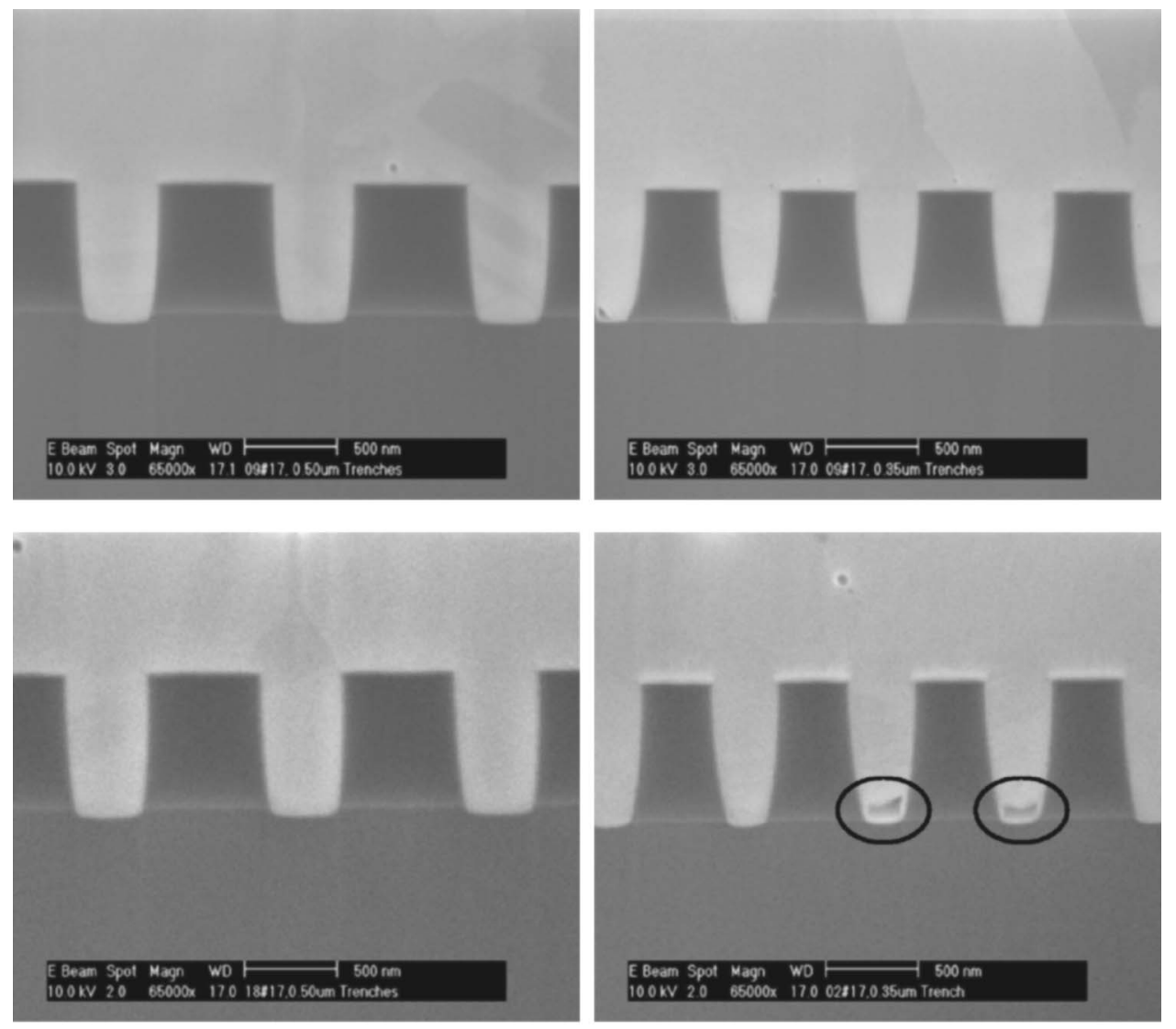

Figure 8. Representative 65000 times tiltview electron images of the $0.50 \mu \mathrm{m}$ (left) and $0.35 \mu \mathrm{m}$ (right) trenches for experimental conditions 3 (top), 6 (middle), and 9 (bottom).
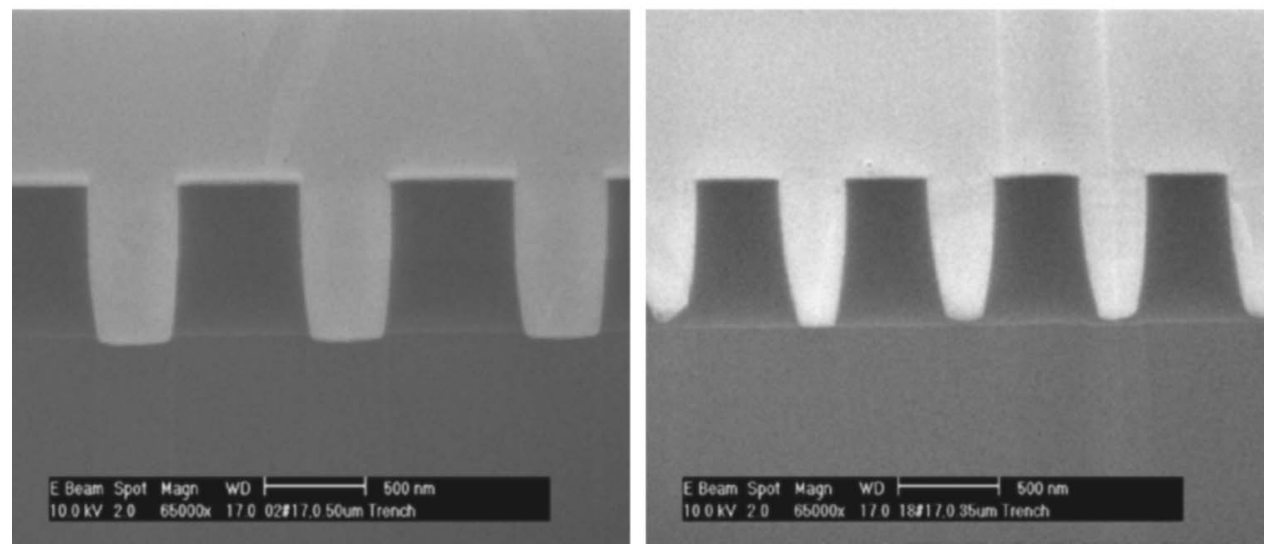

\section{Conclusions}

The recrystallized cross-sectional microstructure within 0.50 and $0.35 \mu \mathrm{m}$ Damascene trench features was examined for nine unique jet electroplating conditions that varied both the current density and brightening additive levels. To investigate any possible remnant effects of current density or brightener level within these trench features, the cross-sectional grain densities (grains $/ \mu \mathrm{m}^{2}$ ) were analyzed within both feature sizes for all nine experimental conditions.

Within the $0.5 \mu \mathrm{m}$ Damascene trenches, it was found that the electroplating current density had a comparatively minor effect on the grain density, whereas the additive level, or the interaction of the additive level with current density, had no significant effect. Increasing the current density within a range of $15-105 \mathrm{~mA} / \mathrm{cm}^{2}$ resulted in moderately smaller average grain densities, or larger average grain sizes. When considering only the extreme values of current density for all three additive levels, the magnitude of the change was approximately $16 \%$ and found to be statistically significant.
A grain density analysis within the smaller $0.35 \mu \mathrm{m}$ features revealed that increasing the current density and decreasing the brightener level had a positive influence on grain size. The current density was found to be the dominant effect and had a much greater influence than that found in the $0.50 \mu \mathrm{m}$ trenches. When considering again only the extreme values of current density, the magnitude of the grain density change ranged between 34 and 47\%, depending on the additive level.

Further examination of the $0.35 \mu \mathrm{m}$ grain density data revealed two distinctly different behaviors with respect to these two electroplating variables. Within a current density range of $15-45 \mathrm{~mA} / \mathrm{cm}^{2}$, the additive level was found to be the dominant effect in producing larger grain sizes within this feature size. The current density was found to be the dominant effect in producing larger grain sizes within a current density range $45-105 \mathrm{~mA} / \mathrm{cm}^{2}$.

In considering both the 0.35 and $0.50 \mu \mathrm{m}$ grain density results, it appears that current density, and to a lesser extent additive level, will 
play a much more dominant role in determining the final grain size in Damascene trenches, as interconnect geometries become smaller in conjunction with increasing aspect ratios. Even without specific knowledge of the mechanisms leading to these dependencies in the trench features, it appears that the level of geometrical constraint, the number of available nucleation sites, the amount of stored energy in the microstructure, and the degree of additive incorporation in these interconnect films are factors to be considered. article.

San Jose State University assisted in meeting the publication costs of this

\section{References}

1. A. Tzanavaras, G. Young, and S. Gleixner, J. Electrochem. Soc., 152, C101 (2005).

2. G. Tzanavaras and U. Cohen, U.S. Pat. No. 5,421,987 (1995).

3. R. Duva and W. H. Sanfranek, Electroplating Engineering Handbook, 4th ed., pp. 767-773, Van Nostrand Reinhold Company, New York (1984).

4. V. M. Dubin, S. Lopatin, S. Chen, R. Cheung, C. Ryu, and S. S. Wong, Mater. Res. Soc. Symp. Proc., 514, 275 (1998).

5. L. M. Gignac, K. P. Rodbell, C. Cabral, Jr., P. C. Andricacos, P. M. Rice, R. B. Beyers, P. S. Locke, and S. J. Klepeis, Mater. Res. Soc. Symp. Proc., 564, 373 (1999).

6. C. Lingk and M. E. Gross, J. Appl. Phys., 84, 5547 (1998).

7. J. M. E. Harper, C. Cabral, P. C. Andricacos, L. Gignac, I. C. Noyan, K. P. Rodbell, and C. K. Hu, Mater. Res. Soc. Symp. Proc., 564, 387 (1999).

8. S. H. Brongersma, E. Richard, I. Vervoot, K. Maex, and E. Kerr, in Proceedings of the IEEE 2001 International Interconnect Technology Conference, IITC, p. 40 (2001).

9. T. Ritzdorf, L. Graham, D. Clarke, and R. Thakur, Semiconductor Fabtech, 11, 279 (2000).

10. T. Ritzdorf, D. Chen, D. Fulton, and C. Dundas, in Proceedings of the IEEE 1999 International Interconnect Technology Conference, IITC, p. 287 (1999).

11. S. H. Brongersma, E. Richard, I. Vervoot, and K. Maex, in Proceedings of the IEEE 2000 International Interconnect Technology Conference, IITC, p. 31 (2000).

12. Q. T. Jiang, M. E. Thomas, G. Bersuker, B. Foran, R. Mikkola, C. Carpenter, and J. Ormando, Mater. Res. Soc. Symp. Proc., 564, 429 (1999).

13. H. Lee, S. D. Lopatin, A. F. Marshall, and S. S. Wong, in Proceedings of the IEEE
2001 International Interconnect Technology Conference, IITC, p. 46 (2001)

14. S. P. Hau-Riege and C. V. Thompson, Appl. Phys. Lett., 6, 309 (2000).

15. S. H. Brongersma, E. Richard, I. Vervoot, K. Maex, E. Kerr, and A. Saerens, J. Mater. Res., 17, 31 (2002)

16. Q. T. Jiang, M. E. Thomas, G. Bersuker, B. Foran, R. Mikkola, C. Carpenter, and J. Ormando, Mater. Res. Soc. Symp. Proc., 564, 429 (1999).

17. M. Chen, H. S. Shin, R. Cheung, R. Morad, Y. Dordi, S. Rengarajan, and S. Tsai, in Proceedings of the IEEE 2000 International Interconnect Technology Conference, IITC, p. 194 (2000).

18. G. P. Beyer, P. Kitabijan, S. H. Brongersma, H. Bender, E. Richard, I. Vervoort, P Hey, P. Zhang, and K. Maex, Mater. Res. Soc. Symp. Proc., AMC 99, 75 (1999).

19. V. M. Dubin, G. Morales, C. Ryu, and S. S. Wong, Mater Res Soc. Symp. Proc., 505, 137 (1998).

20. V. M. Dubin, C. H. Ting, and R. Cheung, in Proceedings of the ISMIC International VLSI Multilevel Interconnection Conference, VMIC, p. 69 (1997).

21. V. M. Dubin, S. Lopatin, S. Chen, R. Cheung, C. Ryu, and S. S. Wong, Mater. Res. Soc. Symp. Proc., 514, 275 (1998).

22. Copper Damascene CMP Characterization Wafer: SKW 6-2 Mask Documentation, SKW Associates, Inc., Santa Clara, CA (1999).

23. J. W. Dini, Electrodeposition: The Materials Science of Coatings and Substrates, pp. 232-236, Noyes Publications, New York (1993).

24. P. Bratin, G. Chalyt, and M. Pavlov, Plat. Surf. Finish., 14 (2000).

25. FEI Company, Hillsboro, OR, 97124.

26. S. Grunow, D. Diatezua, S. C. Seo, T. Stoner, and A. E. Kaloyeros, Mater. Res Soc. Symp. Proc., 564, 407 (1999).

27. D. Wilcox, B. Dove, D. McDavid, and D. Greer, UTHSCSA Image Tool for Windows (Version 2.00), University of Texas Health Science Center, San Antonio, TX (1996).

28. R. E. Walpole, R. H. Meyers, S. L. Meyers, and K. Ye, Probability \& Statistics for Engineers \& Scientists, 7th ed., p. 555, Prentice Hall, Englewood Cliffs, NJ (2002).

29. M. E. Gross, R. Drese, C. Lingk, W. L. Brown, K. Evans-Lutterodt, D. Barr, D. Golovin, T. Ritzdorf, J. Turner, and L. Graham, Mater. Res. Soc. Symp. Proc., 564 379 (1999).

30. M. Paunovic and M. Schlesinger, Fundamentals of Electrochemical Deposition, pp. 169, and Fundamentals of Electrochemical Deposition, 247-248, John Wiley \& Sons, Inc., New York (1998).

31. K. Musaka, B. Zheng, H. Wang, L. Wijekoon, L. Chen, J. Lin, K. Watanabe, K. Ohira, T. Hosoda, K. Miyata, T. Hasegawa, G. Dixit, R. Chueng, M. Yamada, and S. Dadomura, in Proceedings of the IEEE 2001 International Interconnect Technology Conference, IITC, p. 28 (2001) 